\title{
Erratum to: Impact of Emerging Engine and After-Treatment Technologies for Improved Fuel Efficiency and Emission Reduction for the Future Rail Diesel Engines
}

Carlo Beatrice $^{1} \cdot$ Natale Rispoli $^{2}$ - Gabriele Di Blasio ${ }^{1}$.

Athanasios G. Konstandopoulos ${ }^{3}$ • Eleni Papaioannou ${ }^{3}$ - Abdurrahman Imren ${ }^{4}$

Published online: 1 June 2017

(C) Springer International Publishing Switzerland 2017

Erratum to: Emiss. Control Sci. Technol. (2016) 2(2):99-112

DOI 10.1007/s40825-016-0035-1

The correct affiliation of authors Athanasios G.

Konstandopoulos and Eleni Papaioannou is:

${ }^{2}$ CERTH/CPERI and Aristotle University, Thessaloniki, Greece

The online version of the original article can be found at doi:10.1007/ s40825-016-0035-1

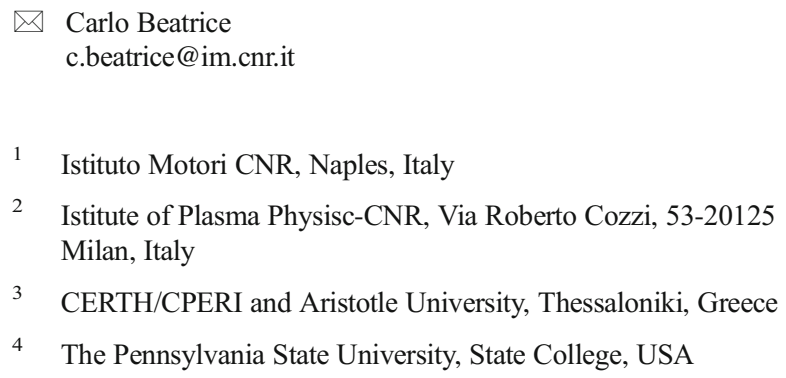

4 The Pennsylvania State University, State College, USA 